\title{
Self-assessment, attitude and perception of interprofessional learning in hospital acquired infection control practices among health professionals in Klang Valley, Malaysia
}

Saraswathy Thangarajoo ${ }^{1,2}$, A. M. Rosliza ${ }^{3}$, Sivalingam Nalliah4, Jalina Karim5, Shamarina Shohaimi ${ }^{6}$, S. Ramasamy ${ }^{7}$ and S. Amin-Nordin ${ }^{*}$

\begin{abstract}
Background: Interprofessional learning (IPL) is a key challenge in Malaysia in incorporating the current professionspecific medical education into the interprofessional learning curriculum. Safe practices would be enhanced with improved collaboration among the health professionals when they learn with, from, and about each other. The main objective of this study was to determine the significant differences in self-assessment, attitude, and perception of interprofessional learning among doctors and nurses in a teaching hospital in Klang Valley, Malaysia. The second objective was to determine if there is any significant difference in the selected demography factors, mean and total scores between doctors and nurses in self-assessment, attitude, and perceptions of IPL aspects.
\end{abstract}

Methods: A total of doctors (39) and nurses (37) were recruited for an interventional study on the interprofessional learning approach on hospital acquired infection control. The participants responded to the University of West England Interprofessional (UWEIP) questionnaire at baseline consisting of four dimensions in IPL aspects; Selfassessment on communication and teamwork skills (CTW), interprofessional learning (IPL), interprofessional interaction (IPI), and interprofessional relationship (IPR). The Cronbach alpha value for the total questionnaire was established at 0.79 .

Results: The majority of doctors scored positive in CTW, IPL, IPR, and neutral in IPI. Nurses' also recorded the highest positive scores in CTW, IPL, and IPR, and neutral in IPI. Negative scores were found in CTW and IPI. A significant difference was revealed between doctors and nurses in IPL attitude; $p=0.024$ and there was no significant difference in other dimensions $(p>05)$. Results also found a significant difference between participants' and non-participants of IPL training sessions; $p=0.009$.

Conclusions: This study revealed the infusion of interprofessional learning training among the health professionals displayed better self-assessments, attitudes, and perceptions towards collaborative practices.

Keywords: Interprofessional, Learning, Self-assessment, Perception, Attitude, Doctor, Nurse

\footnotetext{
*Correspondence: syafinaz@upm.edu.my

'Department of Medical Microbiology, Faculty of Medicine and Health

Sciences, Universiti Putra Malaysia, Serdang, Malaysia

Full list of author information is available at the end of the article
}

(c) The Author(s). 2021 Open Access This article is licensed under a Creative Commons Attribution 4.0 International License, which permits use, sharing, adaptation, distribution and reproduction in any medium or format, as long as you give appropriate credit to the original author(s) and the source, provide a link to the Creative Commons licence, and indicate if changes were made. The images or other third party material in this article are included in the article's Creative Commons licence, unless indicated otherwise in a credit line to the material. If material is not included in the article's Creative Commons licence and your intended use is not permitted by statutory regulation or exceeds the permitted use, you will need to obtain permission directly from the copyright holder. To view a copy of this licence, visit http://creativecommons.org/licenses/by/4.0/. The Creative Commons Public Domain Dedication waiver (http://creativecommons.org/publicdomain/zero/1.0/) applies to the data made available in this article, unless otherwise stated in a credit line to the data. 


\section{Background}

Parallel to the global medical education wave of "Learning together to work together for Health' [1], interprofessional learning (IPL) is a key issue to be addressed in Malaysia.

Interprofessional learning (IPL) refers to "occasions when two or more professionals learn with, from and about each other to improve collaboration and the quality of care". It promotes interdisciplinary collaboration and teamwork, reducing barriers and misconceptions among healthcare providers, resulting in better management of the patient [2].

Interprofessional Education Collaborative Experts Panel in 2011, outlined four IPL core competency domains namely, ethics and values, roles and responsibilities, interprofessional (IP) communication and teams, and teamwork. Six disciplines which consist of dentistry, nursing, medicine, osteopathic medicine, pharmacy, and public health were included in this initiative [3]. The report also guided in preparing future health professionals for collaborative safe patientcentered care. Since then, the core competencies were broadly disseminated to guide curriculum development in medical education.

In 2016, IPEC organized the four competencies within a singular domain of IP collaboration to better improve the 'Triple Aim' which are the patient experience of care, health of population, and reduction of cost of health care. Furthermore, it was also outlined hospital- acquired infection control practices as one of the aspects to begin IPL among health professionals [4].

The establishment of professional collaboration between doctors and nurses gained attention ever since the publication of the hallmark article by Dr. Stein Leonard in 1967 [5].

These professions demand intense mutual respect and cooperation between the team members. The stereotype attitude towards nurses as the handmaiden of male doctors creates serious resistance to ineffective communications between them as the doctors seek information about patient progress from nurses. The doctor-nurse game illustrated nurses need to be bold and have the initiative to make momentous recommendations, but they need to appear passive [5].

Over the years, the progression in nursing became significant as it evolved as a profession with its own autonomy and not merely the handmaiden of doctors and taken professional roles in patient care. In 1990, Stein, Watts, and Howell revisited the doctor-nurses 'game' and they recognised the evolution of nursing practice as a profession parallel to other health professionals [6]. However, since then, the author's opinion became debatable with many studies that have reported the game is still been played. There is a need for greater dialogue as all health professionals are experts in their field and need to collaborate for the good of the patients.

Doctors and nurses as students build their own professional identities, as their training program is different with emphasis varying. New relationships are developed when they enter the profession and share common core values, knowledge, and skills. The "professional silos" often foster interactions based on power, competition, and hierarchies, resulting in insufficient preparation for collaboration among them. They are unrealistically expected to function in collaborative health care teams. Interprofessional learning can introduce shared learning early and help prepare learners for collaborative practice [7]. Furthermore, advances in IPL competencies fostered moving beyond profession-specific educational efforts to engage students of different professions in interactive learning [8].

The main objective of this study was to evaluate the current perception of readiness in interprofessional learning aspects among doctors and nurses in hospital acquired infection control practices. The second objective was to determine if there is any significant difference in the selected demography factors, mean and total scores between doctors and nurses in self-assessment, attitude, and perceptions of IPL aspects.

\section{Barriers in interprofessional learning}

Training healthcare professionals for interprofessional work has an important role in increasing the quality of services rendered to the patient and community at large. Hierarchical questions often result in significant barriers to patient safety and disconnect among professions. Healthcare professions also need to change the way they relate to one another before they can work in collaborative teams [9]. The most effective period to introduce the principles of IPL in the curriculum for training healthcare professionals is still debatable and varies across different institutions [10].

Moreover, organisational hierarchy such as seniority often creates obstacles to the formation of interprofessional collaboration among doctors and nurses. Nurses find that junior doctors are generally more open to suggestions, showing non-competitive roles in patient care [9]. Often junior doctors depend on nurses for essential sources of information as they are prescribing treatment while the senior doctors finalise medical decisions. It is not uncommon to see differences in opinion and decision-making challenges between senior physicians and experienced nurses which is less apparent with junior doctors [11].

This relationship is less apparent between junior doctors and nurses caring for the patient [12]. In a qualitative study by Long et al. on medical dominance in interprofessional collaboration, doctors' opinions were 
often dominant, and non-doctors' opinions were often muted. Doctors' time was appreciated over nurses' time, both within the clinical team and in the broader hospital environment. The doctors' power of speech had more authority and autonomy than nurses [13].

\section{Significance of the interprofessional learning study}

Doctors and nurses in the current study had undergone their training in traditional profession-specific programs. Little evidence is garnered to demonstrate that they possess formal exposure to IPL in their training. Clearly, there is a need to be formally trained in IPL when supervising medical and nursing students during their formative years in order to minimize gaps in clinical practice in IPL. Previous poor experiences within the healthcare team can reinforce negative beliefs about the value of other health professionals to learners [14].

In spite of the growth in the subject of IPL as reported in the literature [15], a search of Malaysian literature showed that there are few studies concerning to aspects of IPL as a medical educational strategy. The case for instructions in IPL is borne by Gambino et al.'s study which shows evaluations for courses on interprofessional teambased learning between medical and nursing students, have been very positive [16]. In fact, early exposure to IPL will allow students to develop their own professional identity together with the knowledge, skills, attitudes, and behaviour that will expedite future collaboration [17].

The hospital where this study was conducted is providing clinical placement for students from various fields. The doctors and nurses are observed by these students as role models. This descriptive comparative study aimed to identify the aspects of IPL among doctors and nurses in the pre-interventional stage of a doctorate study to report on baseline findings.

\section{Methods}

\section{Research design}

This was a cross-sectional study carried out from June 2018 to January 2019.

\section{Research setting}

This study was conducted in Hospital Serdang, which is an affiliated teaching hospital for Universiti Putra Malaysia in Klang Valley, Malaysia. Serdang Hospital is a 620 bedded government-funded multi-specialty hospital located in the district of Sepang in the state of Selangor, Malaysia. It is designated as the tertiary referral center for nephrology, urology, and cardiothoracic surgery. Permission to conduct this study was granted by the Clinical Research Centre of Hospital Serdang. The heads of the departments were approached to recruit participants on a voluntary basis. Purposive sampling was used to recruit participants from medical, surgical, pediatric, emergency, and intensive care units. All participants signed the consent form on a voluntary basis.

\section{Participants \\ Sample size estimation}

Sample size estimation was done using Lehr's equation: [18].

The formula for the sample size to compare two population means, $\mu 0$ and $\mu 1$, with common variance $\partial^{2}$ is:

$$
\mathrm{N}=\frac{[(\mathrm{r}+1 / \mathrm{r})][\mathrm{Z} 1-\alpha / 2+\mathrm{Z} 1-\beta]^{2}}{[(\mu 0-\mu 1) / \partial]^{2}}
$$

Therefore, $\mathrm{N}=\frac{2[1.96+0842]^{2}}{\Omega^{2^{2} / \partial^{2}}}=\frac{15.68}{2 / \partial^{2}}$

$$
=16 / \Delta^{2}
$$

$\alpha$ Significance level set at $5 \%$. Hence, $Z 1-\alpha / 2$ is 1.96 .

$1-\beta$ power set at $80 \%$. Hence, $Z 1-\beta$ is 0.842

$\Omega$ Test value of the difference between two means.

$\partial$ Anticipated SD of the response variable/parameter.

$\Delta$ Standardized Difference is the treatment difference to be detected in units of the standard deviation $=[(\mu 0$ $\mu 1) / \partial]=\Omega 2 / \partial 2$.

$\mathrm{r}$ Ratio of interventions against the controls $=1$.

Here, the design effect is the anticipated standard deviation of the response variable on the intervention.

Based on Flude et al. (2016), mean knowledge in infection control has increased from pretest; $84.95 \%$ (Mean = 5.75; SD 1.09; $n=189)$ to post-test; $($ Mean $=6.25 ; \mathrm{SD}=$ $0.81 ; n=106)$. In this study, the mean difference has been set at 1.00 and $\mathrm{SD}=1.5$ [19]. Eighteen (18) doctors (18); and eighteen (18) nurses are needed for each group (based on Lehr's formula calculation) and the means score is based on a previous study by Flude et al. (2016) [19]; $($ Mean $=6.25, \mathrm{SD}=109)$. However, providing an additional $50 \%$ for attrition rate [20] in order to estimate the loss to follow up at 3 months post-intervention assessment, the total sample size of 54 for each.

intervention and control groups will be fixed with equal numbers of doctors (27) and nurses (27) in each group, totaling 108 participants. The tool used to calculate this sample size is as retrieved from:

http://www.openepi.com/SampleSize/SSMean.htm

\section{Inclusion criteria}

The inclusion criteria include consist of doctors and nurses working in the high risk and medium risk areas in hospital acquired infections. Due to the constraints in getting the number of participants, medical and surgical wards were also included. 


\section{Exclusion criteria}

Doctors and nurses who are not consenting to the study, maternity leave and annual leave on days of data collection were excluded in this study.

\section{Instruments}

The University of West England (UWE) Interprofessional (IP) questionnaire was selected as the instrument to be used. A pool of professionals including nursing faculty was involved in the validation of the questionnaire. The questionnaire consists of four dimensions measures the construct of interprofessional learning:

\section{i. Communication and Teamwork (CTW) \\ ii. Interprofessional Learning (IPL) \\ iii. Interprofessional Interaction (IPI) \\ iv. Interprofessional Relationship (IPR)}

The objective of the questionnaire is to measure selfassessment on communication and teamwork skills, attitude and perceptions towards interprofessional learning and interaction, and on relationships among disciplines. The CTW, IPL and IPR were developed by Pollard et al. (2004). The reliability coefficients measured using Cronbach alpha obtained were $0.76(n=813), 0.84(n=836)$ and $0.82(n=825)$ respectively [21]. The IPR dimension was tested by Pollard et al.(2005) and the overall Cronbach alpha was $0.71(n=694)$ [22]. The stability of the questionnaire was tested using a test-retest method. Permission has been granted by Dr. Katherine Pollard to use the questionnaire for this study.

Concurrent validity was established for each dimension. The teamwork and communication scale responses were compared to those of the Interpersonal Communication Competence Scale [23], and responses to the scale concerning interprofessional learning with those to the Readiness for Interprofessional Learning Scale respectively [24]. The Interprofessional Interaction Scale was supported by qualitative data from students' interview on perception towards interprofessional interaction in healthcare [21] and Interprofessional Relationships Scale was compared with the Interdisciplinary Education Perception Scale by Leucht et al. (1990) [25] as reported by Pollard et al. in 2005 [22].

Three (3) expert panels consisting of two medical specialists with interprofessional teaching and clinical expertise and one Deputy Director of Nursing from the Nursing Board Malaysia with vast clinical expertise, validated the contents using a 4-point relevance scale [26]. The three experts scored 'Very relevant' to all the 35 items and no changes were made to the items. The questionnaire was piloted in the local settings among 15 doctors and 15 nurses. Negative items were recoded as recommended by the developer e.g. the third item in the CTW dimension 'I have difficulty in adapting my communication style (oral and written) to situations and audiences'. The scores are then summed to produce a composite score. The Cronbach alpha for the 4 subscales was CTW (.552), IPL (.816), IPI (.675) and IPR (.775). The overall Cronbach reliability with a total of 35 items was established at 793 .

The scores assigned for each dimension to categorise the achievements indicating positive, neutral and negative are as follows:

i. Self- assessment on Communication and teamwork (CTW)

- Nine statements on self-assessment of communication and teamwork skills were tested in the Communication and Teamwork (CTW) dimension. A 4point Likert scale was scored from 1 (strongly agree) to 4 (strongly disagree). The neutral point was omitted as all participants are presumed to have experience in communication and group work at an informal level. The maximum score for this scale is 36 , while the minimum is 9 . Scores from 9 to 20 , $21-25$, and $26-36$ are considered to indicate positive, neutral and negative attitudes respectively towards self-assessment of communication and teamwork.

ii. Attitude in interprofessional learning (IPL) and perception in interprofessional interaction (IPI)

- Five-point Likert scale was used; 1 (strongly agree) to 5 (strongly disagree). For the Interprofessional Learning (IPL) and Interprofessional Interaction Scales (IPI), scores from 9 to 22, 23-31, and 32-45 indicate positive, neutral, and negative attitudes respectively towards interprofessional learning and perceptions of interprofessional interaction (both these scales have a maximum score of 45 and a minimum of 9).

- The IPL dimension consists of 9 statements on attitude towards interprofessional learning. The statements tested how doctors feel about working together with nurses and vice versa.

- The IPI dimension consists of 9 statements on the perception of interprofessional interaction between doctors and nurses [20].

\section{iii. Attitude in interprofessional relationship (IPR)}

- The Interprofessional Relationships dimension has a maximum score of 40 and a minimum of 8 . Scores from 8 to 20, 21-27, and 28-40 indicate positive, neutral, and negative attitudes respectively towards the respondent's own interprofessional relationships. 
The IPR scale tested on attitudes towards the relationship between doctors and nurses with 3 statements from their own discipline and 5 statements from other disciplines [22]. The IPL data was collected by face-face administration among participants in a study briefing session.

\section{Data analysis}

Data analysis was carried out in two phases. First, a descriptive analysis was done, using frequency and percentage for sociodemographic data. Total scores were tabulated on the four dimensions results. Subsequently, the scores were compared by means between doctors and nurses to determine the significant difference in the scores. Homogeneity of variances and the normality of the distribution were tested by calculating skewness and kurtosis. The data were normally distributed and variances in the groups were homogeneous. Parametric tests were used in the statistical analysis.

An independent $\mathrm{t}$-test was used to determine the significant difference between gender and participants and non-participants of IPL sessions. One-way ANOVA was carried out to assess the significant difference in age, highest qualifications, and years of practice. Statistical analysis was conducted using SPSS version 23.0 (SPSS Inc.) and a $p<0.05$ was adopted as a decision criterion. Internal consistency measured using Cronbach's alpha was $0.79(n=76)$, Therefore the questionnaire satisfies conditions for adequate reliability of 0.7 [27].

\section{Results}

The total number of participants in this study consist of 39 doctors and 37 nurses (Table 1). Most of the doctors (94.9\%) and nurses $(45.9 \%)$ are from the age group of $25-30$ years. Doctors consist of $43.6 \%$ males and $56.4 \%$ females, whereas the majority of nurses were females. Nurses (40.5\%) attended IPL training as compared to doctors $(15.4 \%)$.

Table 2 describes the analysis of individual items across two dimensions, self-assessment on communication and teamwork (CTW) and interprofessional learning (IPL). Nine items were administered in each dimension. In CTW, the highest agreement was seen in item number 5 on their comfort in working with other staff in a group, with doctors responded, 'strongly agree" (38.5\%) and 'agree' (48.7\%) and; nurses recorded 56.8\% 'strongly agree' and $35.1 \%$ 'agree'. The highest disagreement was revealed on item number 7; 'I feel uncomfortable putting forward my personal opinions in a group'. Doctors scored 43.6\% ('disagree') and 5.1\% ('strongly disagree'); compared to nurses $35.1 \%$ ('disagree') and $5.4 \%$ ('strongly disagree').

The IPL dimension measured on 9 items pertaining to attitudes on learning together between doctors and
Table 1 Description of analysis on demographic data

\begin{tabular}{lll}
\hline & $\begin{array}{l}\text { Doctors }(\boldsymbol{n}=\mathbf{3 9}) \\
\mathbf{n}(\%)\end{array}$ & $\begin{array}{l}\text { Nurses }(\boldsymbol{n}=\mathbf{3 7}) \\
\mathbf{n}(\%)\end{array}$ \\
\hline Age (years) & $37(94.9)$ & $17(45.9)$ \\
$25-30$ & $2(5.1)$ & $13(35.1)$ \\
$31-35$ & & $4(10.8)$ \\
$36-40$ & & $3(8.1)$ \\
40 and above & & \\
Gender & $17(43.6)$ & $2(5.4)$ \\
Male & $22(56.4)$ & $35(94.6)$ \\
Female & & \\
Highest qualification & $39(100)$ & $34(91.9)$ \\
MBBS & & $3(8.1)$ \\
Diploma in Nursing & & \\
Bachelor of Nursing & & $9(24.3)$ \\
Discipline working & & $9(24.3)$ \\
Surgical & $20(51.3)$ & $2(5.4)$ \\
Medical & $6(15.4)$ & $9(24.3)$ \\
Paediatric & $5(12.8)$ & $8(21.6)$ \\
Intensive Care Unit & $1(2.6)$ & $14(37.5)$ \\
Emergency (ED) & $7(17.9)$ & \\
Years of Practice & & \\
1-5 & $39(100)$ & \\
6-10 & & \\
11-15 & & \\
16 and above & & \\
IPL Training & & \\
Yttendees & & \\
Nos & & \\
\hline
\end{tabular}

nurses. The highest agreement among doctors and nurses are seen in item number 18; 'Learning with doctors/nurses is likely to improve the service for patient'. The doctors scored 43.6\% ('strongly agree') and 48.7\% 'agree'. The nurses scored lower comparatively as $27 \%$ ('strongly agree') and 56.8\% 'agree'.

Table 3 shows the analysis of interprofessional interaction (IPI) and interprofessional relationship (IPR) dimensions. Nine items were measured in IPI. The highest agreement scores were among nurses on item number 23; 'All members of medical and nursing professions have equal respect for each discipline' The nurses revealed the highest agreement on this item with $35.1 \%$ 'strongly agree' and $43.2 \%$ 'agree'. In the IPR dimension, eight items were tested. Item number 44 on; 'I lack confidence when I work with people from doctors/nurses' disciplines' scored the highest agreement among doctors. 
Table 2 Analysis of items on Communication and Teamwork and Interprofessional Learning

\begin{tabular}{|c|c|c|c|c|c|c|c|c|c|c|}
\hline \multirow[t]{2}{*}{$\begin{array}{l}\text { Item } \\
\text { Communication and Teamwork }\end{array}$} & \multicolumn{2}{|c|}{$\begin{array}{l}\text { Strongly } \\
\text { Agree } \\
(\%)\end{array}$} & \multicolumn{2}{|c|}{$\begin{array}{l}\text { Agree } \\
(\%)\end{array}$} & \multicolumn{2}{|c|}{$\begin{array}{l}\text { Neutral } \\
(\%)\end{array}$} & \multicolumn{2}{|c|}{$\begin{array}{l}\text { Disagree } \\
(\%)\end{array}$} & \multicolumn{2}{|c|}{$\begin{array}{l}\text { Strongly } \\
\text { Disagree } \\
\text { (\%) }\end{array}$} \\
\hline & $\mathrm{D}$ & $\mathbf{N}$ & $\mathrm{D}$ & $\mathbf{N}$ & $\mathrm{D}$ & $\mathrm{N}$ & $\bar{D}$ & $\mathrm{~N}$ & $\mathrm{D}$ & $\mathbf{N}$ \\
\hline $\begin{array}{l}\text { 1.I feel comfortable justifying recommendations /advice face to face with more senior } \\
\text { people }\end{array}$ & 33.3 & 27 & 35.9 & 48.6 & - & - & 28.2 & 24.3 & 2.6 & - \\
\hline 2.I feel comfortable explaining an issue to people who are unfamiliar with the topic & 25.6 & 16.2 & 48.7 & 48.6 & - & - & 25.6 & 32.4 & - & 2.7 \\
\hline $\begin{array}{l}\text { 3.I have difficulty in adapting my communication style (oral and written) to particular } \\
\text { situations and audiences }\end{array}$ & 2.6 & 13.5 & 59 & 54.1 & - & - & 33.3 & 32.4 & 5.1 & - \\
\hline $\begin{array}{l}\text { 4.I prefer to stay quiet when other people in a group express opinion that I don't agree } \\
\text { with }\end{array}$ & 10.3 & 18.9 & 51.3 & 64.9 & - & - & 25.6 & 16.2 & 12.8 & - \\
\hline 5.I feel comfortable working in a group & 38.5 & 56.8 & 48.7 & 35.1 & - & - & 7.7 & 8.1 & 5.1 & - \\
\hline 6.I feel uncomfortable putting forward my personal opinions in a group & 12.8 & 32.4 & 38.5 & 27 & - & - & 43.6 & 35.1 & 5.1 & 5.4 \\
\hline 7.I feel uncomfortable taking the lead in a group & 15.4 & 24.3 & 41 & 37.8 & - & - & 35.9 & 32.4 & 7.7 & 5.4 \\
\hline 8.I am able to become quickly involved in new teams and groups & 20.5 & 21.6 & 48.7 & 43.2 & - & - & 30.8 & 35.1 & - & - \\
\hline $\begin{array}{l}\text { 9.I am comfortable expressing my own opinions in a group, even when I know that other } \\
\text { people don't agree with them }\end{array}$ & 17.9 & 13.5 & 41 & 45.6 & - & - & 41 & 32.4 & - & 8.1 \\
\hline \multicolumn{11}{|l|}{ Interprofessional Learning } \\
\hline $\begin{array}{l}\text { 10.My skills in communicating with patients/clients would be improved through } \\
\text { learning with doctors/ nurses }\end{array}$ & 35.9 & 24.3 & 51.3 & 51.4 & 7.7 & 21.6 & 5.1 & - & - & 2.7 \\
\hline $\begin{array}{l}\text { 11.My skills in communicating with doctors/nurses would be improved through learning } \\
\text { with them. }\end{array}$ & 48.7 & 32.4 & 43.6 & 45.9 & 5.1 & 18.9 & - & 2.7 & 2.6 & - \\
\hline 12.I would prefer to learn only with peers from my own profession & 30.8 & 32.4 & 33.3 & 45.9 & 10.3 & 10.8 & 15.4 & 5.4 & 10.3 & 5.4 \\
\hline $\begin{array}{l}\text { 13.Learning with doctors/nurses is likely to facilitate subsequent working professional } \\
\text { relationships }\end{array}$ & 41 & 21.6 & 48.7 & 43.2 & 10.3 & 24.3 & - & 2.7 & - & 8.1 \\
\hline $\begin{array}{l}\text { 14.Learning with doctors/nurses would be more beneficial to improving my teamwork } \\
\text { skills than learning only with my peers. }\end{array}$ & 33.3 & 13.5 & 48.7 & 48.6 & 12.8 & 24.3 & 2.6 & 2.7 & 2.6 & 10.8 \\
\hline $\begin{array}{l}\text { 15.Collaborative learning would be a positive learning experience for all doctors and } \\
\text { nurses }\end{array}$ & 46.2 & 40.5 & 43.6 & 43.2 & 7.7 & 13.5 & 2.6 & - & - & 2.7 \\
\hline $\begin{array}{l}\text { 16.Learning with doctors/nurses is likely to help to overcome stereotypes that are held } \\
\text { about the different professions }\end{array}$ & 43.6 & 16.2 & 48.7 & 51.4 & 5.1 & 29.7 & 2.6 & 2.7 & - & - \\
\hline 17.I would enjoy the opportunity to learn with doctors/nurses & 33.3 & 29.7 & 56.4 & 56.8 & 10.3 & 13.5 & - & - & - & - \\
\hline 18.Learning with doctors/nurses is likely to improve the service for patient/client & 43.6 & 27 & 48.7 & 56.8 & 7.7 & 16.2 & - & - & - & - \\
\hline
\end{tabular}

They scored 46.2\% ('strongly agree') and 48.7\% 'agree' but nurses recorded only $24.3 \%$ ('strongly agree'), $21.6 \%$ ('agree').

As displayed in Table 4, the majority of the participants scored positively on self-assessment of communication and teamwork (CTW) skills with higher scores among nurses 70.3\% [Mdn $=19 ; 95 \%$ CI $(16.5,21.5)]$ compared to doctors $59 \%$ [Mdn $=19,95 \%$ CI $(17,22)]$. Nurses scored $11.3 \%$ more positive than doctors. In interprofessional learning dimension, most of the doctors 92.3\% [Mdn $=17,95 \%$ CI $(12,19)]$ recorded positive attitude scores compared to nurses only $83.8 \%$ [Mdn $=18$, 95\% CI $(16,20)]$. This finding shows doctors scored 8.5\% more positive attitude towards interprofessional learning as compared to nurses.

Interprofessional interaction dimension revealed doctors showed higher neutral perception, 64.1\% [Mdn $=27$, 95\% CI $(24,31)]$ compared to nurses $51.4 \%[\mathrm{Mdn}=27$,
95\% CI $(23,32.5)]$. This finding showed $6.2 \%$ of nurses have a more positive perception towards interprofessional interaction as compared to doctors. In interprofessional relationship (IPR) dimension, $84.6 \%$ doctors $[\mathrm{Mdn}=18,95 \%$ CI $(15,20)]$ revealed positive attitude compared to $70.3 \%$ among nurses $[\mathrm{Mdn}=19,95 \% \mathrm{CI}$ $(14,21)]$. This finding showed doctors revealed $14.3 \%$ higher positive attitude than nurses in IPR.

\section{Mean description of the dimensions}

Table 5 shows the tabulation of $t$ values for an independent $t$-test across four dimensions of IPL. The mean scores of the IPI are the highest among the 4 dimensions, whereas IPL has the lowest mean scores. Levene's test is not violated, indicating the data are homogeneously distributed across both groups. There was no significant difference between doctors and nurses in CTW; t $(74)=1.200, p=0.234$, IPI; $\mathrm{t}(74)=.644, p=.522$ 
Table 3 Analysis of Interprofessional Interaction and Interprofessional relationship Dimensions

\begin{tabular}{|c|c|c|c|c|c|c|c|c|c|c|}
\hline \multirow[t]{2}{*}{$\begin{array}{l}\text { Item } \\
\text { Interprofessional Interaction Scale }\end{array}$} & \multicolumn{2}{|c|}{$\begin{array}{l}\text { Strongly } \\
\text { Agree } \\
\text { (\%) }\end{array}$} & \multicolumn{2}{|c|}{$\begin{array}{l}\text { Agree } \\
(\%)\end{array}$} & \multicolumn{2}{|c|}{$\begin{array}{l}\text { Neutral } \\
(\%)\end{array}$} & \multicolumn{2}{|c|}{$\begin{array}{l}\text { Disagree } \\
(\%)\end{array}$} & \multicolumn{2}{|c|}{$\begin{array}{l}\text { Strongly } \\
\text { disagree } \\
\text { (\%) }\end{array}$} \\
\hline & $\mathrm{D}$ & $\mathbf{N}$ & $\mathrm{D}$ & $\mathbf{N}$ & $\mathrm{D}$ & $\mathbf{N}$ & $\mathrm{D}$ & $\mathbf{N}$ & $\mathrm{D}$ & $\mathbf{N}$ \\
\hline 19.Doctors and nurses have stereotyped views of each other. & 5.1 & - & 5.1 & 13.5 & 33.3 & 18.9 & 38.5 & 43.2 & 17.9 & 24.3 \\
\hline $\begin{array}{l}\text { 20.The line of communication between all members of the doctors and nursing } \\
\text { professions is open }\end{array}$ & 20.5 & 35.1 & 35.9 & 37.8 & 28.2 & 13.5 & 10.3 & 13.5 & 5.1 & - \\
\hline $\begin{array}{l}\text { 21.There is a status hierarchy in health care that affects relationships between doctors and } \\
\text { nursing professionals. }\end{array}$ & 2.6 & 13.5 & 17.9 & 10.8 & 25.6 & 16.2 & 43.6 & 37.8 & 10.3 & 21.6 \\
\hline 22.Doctors and nursing professionals are biased in their views of each other. & 2.6 & 10.8 & 15.4 & 18.9 & 46.2 & 18.9 & 23.1 & 37.8 & 12.8 & 13.5 \\
\hline 23.All members of medical and nursing professions have equal respect for each discipline. & 25.6 & 35.1 & 30.8 & 43.2 & 20.5 & 8.1 & 17.9 & 10.8 & 5.1 & 2.7 \\
\hline 24.It is easy to communicate openly with people from other health care disciplines. & 7.7 & 21.6 & 43.6 & 43.2 & 33.3 & 18.9 & 12.8 & 16.2 & 2.6 & - \\
\hline 25.Not all relationships between medical and nursing professionals are equal & - & 2.7 & 2.6 & 2.7 & 43.6 & 21.6 & 41 & 43.2 & 12.8 & 29.7 \\
\hline $\begin{array}{l}\text { 26.Doctors and nursing professionals do not always communicate openly with one } \\
\text { another. }\end{array}$ & 7.7 & 13.5 & 17.9 & 16.2 & 30.8 & 21.6 & 38.5 & 27 & 5.1 & 21.6 \\
\hline 27.Doctors and nursing professionals are not always cooperative with one another & 12.8 & 24.3 & 17.9 & 24.3 & 30.8 & 21.6 & 33.3 & 18.9 & 5.1 & 10.8 \\
\hline \multicolumn{11}{|l|}{ Interprofessional Relationship Scale } \\
\hline 28.I have an equal relationship with peers from my own professional discipline & 28.2 & 21.6 & 48.7 & 40.5 & 20.5 & 29.7 & 2.6 & 5.4 & - & 2.7 \\
\hline $\begin{array}{l}\text { 29.I am confident in my relationships with my peers from my own professional } \\
\text { discipline }\end{array}$ & 23.1 & 32.4 & 59 & 45.9 & 15.4 & 13.5 & 2.6 & 8.1 & - & - \\
\hline 30.I have a good understanding of the roles of doctors/nurses' professionals. & 17.9 & 16.2 & 43.6 & 48.6 & 33.3 & 32.4 & 5.1 & 2.7 & - & - \\
\hline 31.I am confident in my relationships with people from doctors/nurses' disciplines & 12.8 & 16.2 & 61.5 & 51.4 & 20.5 & 27 & 5.1 & 5.4 & - & - \\
\hline 32.l am comfortable working with people from doctors/nurses disciplines. & 25.6 & 21.6 & 59 & 37.8 & 12.8 & 35.1 & 2.6 & 5.4 & - & - \\
\hline 33.I feel that I am respected by people from doctors/nurses' disciplines & 20.5 & 21.6 & 38.5 & 35.1 & 30.8 & 35.1 & 10.3 & 5.4 & - & 2.7 \\
\hline 34.I lack confidence when I work with people from doctors/nurses' disciplines. & 46.2 & 24.3 & 48.7 & 21.6 & 5.1 & 32.4 & - & 21.6 & - & - \\
\hline 35.I am comfortable working with people from own professional discipline & 12.8 & 48.6 & 59 & 35.1 & 25.6 & 10.8 & 2.6 & 2.7 & - & 2.7 \\
\hline
\end{tabular}

Table 4 Analysis of scores for aspects on interprofessional learning

\begin{tabular}{|c|c|c|c|c|c|c|c|c|c|c|c|c|}
\hline \multirow[t]{3}{*}{ Dimension } & \multicolumn{6}{|c|}{ Indication scores } & \multicolumn{6}{|c|}{ Scores } \\
\hline & \multicolumn{2}{|l|}{$\begin{array}{l}\text { Positive } \\
(9-20)\end{array}$} & \multicolumn{2}{|l|}{$\begin{array}{l}\text { Neutral } \\
(21-25)\end{array}$} & \multicolumn{2}{|l|}{$\begin{array}{l}\text { Negative } \\
(26-36)\end{array}$} & \multicolumn{2}{|c|}{$\begin{array}{l}\text { Max } \\
(36)\end{array}$} & \multicolumn{2}{|c|}{$\begin{array}{l}\text { Min } \\
(9)\end{array}$} & \multicolumn{2}{|c|}{$\begin{array}{l}\text { Median } \\
\text { (Range) }\end{array}$} \\
\hline & $(\%)$ & & $(\%)$ & & (\%) & & & & & & & \\
\hline \multirow{2}{*}{$\begin{array}{l}\text { Communication and Teamwork Scale } \\
\text { (CTW) }\end{array}$} & $\mathrm{D}$ & $N$ & $\mathrm{D}$ & $\mathrm{N}$ & $\mathrm{D}$ & $N$ & $\mathrm{D}$ & $N$ & $\mathrm{D}$ & $\mathrm{N}$ & $\mathrm{D}$ & $\mathrm{N}$ \\
\hline & $23(59)$ & $26(70.3)$ & $14(35.9)$ & $10(27)$ & $2(5.1)$ & $1(2.7)$ & 27 & 28 & 14 & 9 & $19(13)$ & 19 (19) \\
\hline $\begin{array}{l}\text { Interprofessional Learning Scale } \\
\text { (IPL) }\end{array}$ & \multicolumn{2}{|l|}{$\begin{array}{l}\text { Positive } \\
(9-22) \\
f(\%)\end{array}$} & \multicolumn{2}{|l|}{$\begin{array}{l}\text { Neutral } \\
(23-31) \\
f(\%)\end{array}$} & \multicolumn{2}{|l|}{$\begin{array}{l}\text { Negative } \\
(32-45) \\
f(\%)\end{array}$} & \multicolumn{2}{|c|}{$\begin{array}{l}\operatorname{Max} \\
(45)\end{array}$} & \multicolumn{2}{|c|}{$\begin{array}{l}\text { Min } \\
(9)\end{array}$} & \multicolumn{2}{|l|}{$\begin{array}{l}\text { Median } \\
\text { (Range) }\end{array}$} \\
\hline Scores & $31(92.3)$ & $31(83.8)$ & $3(7.7)$ & $6(6.2)$ & Nil & $\mathrm{Nil}$ & 28 & 28 & 9 & 10 & $17(19)$ & $18(18)$ \\
\hline \multicolumn{13}{|l|}{ Interprofessional Interaction (IPI) Scale } \\
\hline \multirow[t]{2}{*}{ Scores } & $6(15.4)$ & $8(21.6)$ & $25(64.1)$ & $19(51.4)$ & $8(20.5)$ & $10(27)$ & 41 & 37 & 16 & 13 & $27(25)$ & $27(24)$ \\
\hline & \multicolumn{2}{|l|}{ Positive } & \multicolumn{2}{|l|}{ Neutral } & \multicolumn{2}{|l|}{ Negative } & \multicolumn{2}{|c|}{$\begin{array}{l}\operatorname{Max} \\
(40)\end{array}$} & \multicolumn{2}{|c|}{$\begin{array}{l}\operatorname{Min} \\
(8)\end{array}$} & & \\
\hline $\begin{array}{l}\text { Interprofessional } \\
\text { Relationship Scale } \\
\text { (IPR) }\end{array}$ & \multicolumn{2}{|c|}{$8-20$} & \multicolumn{2}{|l|}{$21-27$} & \multicolumn{2}{|l|}{$28-40$} & & & & & & \\
\hline Scores & 33 (84.6) & $26(70.3)$ & $6(15.4)$ & $11(29.7)$ & $\mathrm{Nil}$ & $\mathrm{Nil}$ & 23 & 26 & 11 & 8 & $18(12)$ & 19 (18) \\
\hline
\end{tabular}


Table 5 Comparison of mean in aspects on interprofessional learning dimensions among doctors and nurses

\begin{tabular}{lllllll}
\hline Dimension & Mean Score \pm SD among Doctors & $\begin{array}{l}\text { Mean Score } \pm \\
\text { SD among Nurses }\end{array}$ & F & t & df & -value \\
\hline Communication and teamwork & $2.19(.386)$ & $2.08(.454)$ & .094 & 1.200 & 74 & .234 \\
Interprofessional Learning & $1.80(.534)$ & $2.06(.440)$ & 1.744 & -2.305 & 74 & .024 \\
Interprofessional Interaction & $3.06(.585)$ & $2.97(.669)$ & .886 & .644 & 74 & .522 \\
Interprofessional Relationship & $2.16(.397)$ & $2.19(.536)$ & 6.403 & -.298 & 74 & .766 \\
\hline
\end{tabular}

$M$ Mean score; SD Standard deviation

and IPR; $\mathrm{t}(74)=-.298, p=.766$. Whereas, a significant difference was shown in the IPL dimension between doctors and nurses; $\mathrm{t}(74)=-2.305, p=0.024$, wherein nurses showed a higher attitude toward IPL.

Table 6 describes the results for independent t-test conducted to test the significant difference between male and female and; those who attended and did not attend training in interprofessional learning. There was no significant difference in interprofessional learning aspects between male $(\mathrm{M}=2.33, \mathrm{SD}=.319)$ and female $(\mathrm{M}=$ $2.31, \mathrm{SD}=.320)$; t $(74)=.254, p=0.800$. However, a significant difference was found between the participants $(\mathrm{M}=2.16, \mathrm{SD}=.326)$ and non-participants (Mean $=2.38$, $\mathrm{SD}=0.298)$ of IPL sessions; $\mathrm{t}(74)=-2.698, p=.009$. However, the IPL training non-participants scored slightly higher mean scores compared to the participants. This may be influenced by collaborative working experiences among doctors and nurses and contributed to the interprofessional attitude and perception scores.

One-way Anova was conducted to test the significant difference by age, highest educational qualifications, and years in practice in Interprofessional learning aspects (Table 7). There were no significant differences in interprofessional learning aspects by age, $\mathrm{F}(3,72)=0.769$, $p>0.05$. Similar results were revealed for highest qualification, $\mathrm{F}(2,73)=0.120, p>0.05$ and years in practice, $\mathrm{F}$ $(3,72)=.508, p>0.05$.

\section{Discussion}

This study shows doctors and nurses differ in their communication skills although they are required to work collaboratively. Doctors showed a higher inclination towards communication skills compared to nurses through learning with each other. Nurses preferred to stay quiet when other healthcare staff in a group express the opinion of disagreement. Communication among health

Table 6 Independent t-test on demographic factors in interprofessional learning among doctors and nurses

\begin{tabular}{lllll}
\hline $\begin{array}{l}\text { Demographic } \\
\text { Factor }\end{array}$ & $\mathbf{F}$ & $\mathbf{t}$ & $\mathbf{d f}$ & $\boldsymbol{p}$-value \\
\hline Gender & .038 & .254 & 74 & .800 \\
Attend sessions & .174 & -2.698 & 74 & .009 \\
\hline
\end{tabular}

M Mean score; SD Standard deviation professionals is mandatory to deliver safe healthcare and the inequality shown could cause serious consequences, particularly when healthcare providers like nurses are reluctant to express opinions.

In this study, an approximately equal number of doctors and nurses showed agreement to the existence of the status hierarchy in health care systems that affects relationships between doctors and nursing. This finding is consistent with the previous study by Weller et al. stating that junior doctors and nurses expressed mutual respect. However, the junior doctors feel organisational structures such as hierarchy which explicitly requires them to follow seniors often limited the extent to which they could establish trust and effective relationships with nurses [11].

Respect for each discipline is much needed by all doctors and nurses. There exist verbal outbursts by surgeons such as blaming, yelling, or threatening, causing frustration and feelings of incompetence on nursing staff. The personal attacks made by surgeons also created a strong emotional response from the nurses and would cause nurses to resign their positions or to take steps to avoid working with a particular surgeon again [28]. However, in this study, more nurses agreed that they had equal respect in each discipline they worked. It is depicted in previous studies that doctors and nurses need to portray mutual respect to avoid impairment in collaboration at work.

This study found the majority of the nurses have a positive attitude on self-assessment of communication and teamwork skills as compared to doctors. Though there were no significant differences in all the IPL aspects related to age and years of working experience, some of the nurses are from the older age group and with more years of working experience compared to doctors. The nurses' maturity level could have contributed to their higher scores over doctors. Similarly, Pollard et al. reported maturity of participants also plays an important role as the level of confidence among matured learners was higher compared to younger students about their communication and teamwork skills [22].

In the IPL dimension, most of the doctors recorded positive attitude scores compared to nurses. Consistent with previous findings, the strongly positive scores 
Table 7 Analysis of Variance (ANOVA) in the interprofessional learning (IPL) aspects by demographic factors

\begin{tabular}{|c|c|c|c|c|c|c|}
\hline $\begin{array}{l}\text { Demography } \\
\text { Factor }\end{array}$ & & Sum of Squares & Degree of freedom & $\begin{array}{l}\text { Mean } \\
\text { Square }\end{array}$ & $\begin{array}{l}\mathrm{F} \\
\text { Value }\end{array}$ & Significant \\
\hline \multirow[t]{3}{*}{ Age } & $\begin{array}{l}\text { Between } \\
\text { Groups }\end{array}$ & .235 & 3 & .078 & .769 & .515 \\
\hline & Within Groups & 7.351 & 72 & .102 & & \\
\hline & Total & 7.587 & 75 & & & \\
\hline \multirow[t]{3}{*}{ Highest qualification } & BetweenGroups & .025 & 2 & .012 & .120 & .887 \\
\hline & Within Groups & 7.562 & 73 & .104 & & \\
\hline & Total & 7.587 & 75 & & & \\
\hline \multirow[t]{3}{*}{ Years in practice } & $\begin{array}{l}\text { Between } \\
\text { Groups }\end{array}$ & .157 & 3 & .052 & .508 & .678 \\
\hline & Within Groups & 7.429 & 72 & .103 & & \\
\hline & Total & 7.587 & 75 & & & \\
\hline
\end{tabular}

concerning the IPL dimension, may reflect the awareness of the need for strategies that can enhance interprofessional collaboration [22]. However, in the IPI dimension, both doctors and nurses were less positive. A previous study showed that the negative shift in interprofessional interaction may be attributable to the experience of poor interprofessional interaction in work settings [22].

In the IPR dimension, doctors revealed higher positive responses compared to nurses inconsistent with the previous findings in the IPR dimension. Doctors and nurses may also be more aware of the importance of teamwork for the benefit of patients and sufficiently motivated to develop positive working relationships in practice [22]. The positive self-assessment, attitude, and negative scores found are encouraging. However, neutral and negative scores were still found, and improvement is needed as identified, poor interprofessional collaboration (IPC) can negatively affect the delivery of patient care and other health services. Interventions that address interprofessional collaborative problems have the potential to improve healthcare outcomes [29].

In this study, only the IPL attitude dimension was significantly different between doctors and nurses. There was no significant difference found between doctors and nurses in all the other three dimensions in aspects of IPL. Neutral and negatives scores are also found which requires further initiatives in interprofessional education among the health professionals in the studied hospital. Gambino et al. stated initiatives on IPL sessions are expected resulting in contacts made during the learning sessions among health professionals. These sessions have a huge potential to lead to discussions needed to resolve issues pertaining to IPL and the development of formal interprofessional education [16]. Interprofessional learning experience imparts appreciation and respect towards each other's perspectives in the learning stage and avoids the growth of stereotyped behaviour among health professionals [30].

There was a significant difference between participants and non-participants on IPL training towards attitude and perception towards IPL. Hence, a slightly higher mean score among those non-participants of IPL training could result from the collaborative working experiences. More doctors revealed they lack confidence when they work with nurses. Pollard et al. reported maturity, prior experiences of health care, and higher education qualifications may have a breadth of experiences which, could lead to constructive discussion in interprofessional learning groups [21]. Furthermore, Pollard et al. pointed out although the IPL in the curriculum has the possibility to improve the health care delivery, the emergence of variances in responses based on a professional program proposes that IPL may not certainly influence professional socialization. Health professionals' responses as they mature could be influenced by variables i.e. demographic and own interprofessional relationships leading to the complexity of learning [22].

\section{Recommendation}

The results of this study indicate the need for greater incorporation of IPL in the medical and nursing curriculum. Health institutes and hospitals are encouraged to include IPL training in their routine continuous medical education. The authorities also need to allocate time for the doctors and nurses to officially participate in such training to enhance awareness of the importance of collaboration among doctors and nurses.

\section{Limitations}

Robust evaluation of IPL requires longitudinal studies with longer follow-up periods throughout the course period [31]. This study faced difficulties in recruiting 
participants due to their shift work commitments and busy working schedules. Recruitments were only on a voluntary basis and obtaining the numbers in each category such as juniors and seniors were challenging.

\section{Conclusion}

This study illuminates' contemporary insight on selfassessment, attitude, and perception towards aspects of IPL among doctors and nurses. The gap evident from this study will contribute to the literature on IPL in clinical settings in Malaysia. Continuous formal interprofessional learning training programs have the potential in fostering positive perceptions and attitudes towards IPL. Interprofessional learning opportunities in the workplace will create potential benefits for collaborative practices. The findings of this small study revealed health professionals with IPL training showed a better selfassessment, attitude, and perception towards collaborative practices.

\section{Acknowledgements}

We would like to thank the Director General of Health Malaysia for his permission to publish this article.

\section{Authors' contributions}

ST, RAM, NS, and ANS contributed to the study conception and design, interpretation of data, and critical revision of the manuscript. ST was involved in the literature review, data collection, data analysis, and manuscript drafting. SAN and JK were involved in the study design and critical revision of the manuscript. SS was involved in data analysis, interpretation, RS was involved in data analysis and critical revision of manuscript. All authors read the final manuscript. The author (s) read and approved the final manuscript.

\section{Funding}

This research was funded by the Research Incentive Grant for Teaching and Learning (GIPP) from the Universiti Putra Malaysia, number 10073-9323707.

\section{Availability of data and materials}

The data and materials are not available as this study findings are based on baseline data collected in a doctoral project and need to be submitted to Universiti Putra Malaysia. However, the corresponding author can be contacted on reasonable request.

\section{Declarations}

\section{Ethics approval and consent to participate}

Ethical approval for this study was obtained from the Medical Research and Ethics Committee (MREC), Ministry of Health Malaysia." The registration number is NMRR-16-2852-32986(IIR); Protocol Number: 32986. Informed consent was obtained from participants upon agreeing to participate and confidentially was assured. They were informed there is no risk involved in this study. All methods were carried out in accordance with relevant guidelines and regulations.

\section{Consent for publication}

Consent for publication was obtained from National Institutes of Health, Malaysia.

\section{Competing interests}

The authors declare that they have no competing interests.

\section{Author details}

'Department of Medical Microbiology, Faculty of Medicine and Health Sciences, Universiti Putra Malaysia, Serdang, Malaysia. ${ }^{2}$ International Medical College, Subang Jaya, Malaysia. ${ }^{3}$ Department of Community Health, Faculty of Medicine \& Health Sciences, Universiti Putra, Serdang, Malaysia. ${ }^{4}$ Department of Obstetrics and Gynaecology, Clinical Sciences, International Medical University, Seremban, Malaysia. ${ }^{5}$ Department of Nursing, Faculty of Medicine, Universiti Kebangsaan Malaysia, Bangi, Malaysia. ${ }^{6}$ Department of Biology, Faculty of Science, Universiti Putra Malaysia, Serdang, Malaysia. ${ }^{7}$ Department of Psychology, International Medical University, Bukit Jalil, Kuala Lumpur, Malaysia.

Received: 19 December 2020 Accepted: 5 February 2021

Published online: 26 April 2021

\section{References}

1. WHO. Learning together to work together for health : report of a WHO Study Group on Multiprofessional Education of Health Personnel: the Team Approach [meeting held in Geneva from 12 to 16 October 198. 1988.

2. Zwarenstein M, Atkins J, Barr H, Hammick M, Koppel I, Reeves S. A systematic review of interprofessional education. J Interprof Care. 1999;13(4): 417-24. https://doi.org/10.3109/13561829909010386.

3. IPEC. Core Competencies for Interprofessional Collaborative Practice. 2011.

4. IPEC. Core Competencies for Interprofessional Collaborative Practice : 2016 Update. 2016.

5. Stein LI. The doctor-nurse game. Arch Gen Psychiatry. 1967;16(6):699-703. https://doi.org/10.1001/archpsyc.1967.01730240055009.

6. Stein LI, Watts DT, Howell T. The doctor-nurse game revisited. N Engl J Med. 1990;322(8):546-9. https://doi.org/10.1056/NEJM199002223220810.

7. McNair RP. The case for educating health care students in professionalism as the core content of interprofessional education. Med Educ. 2005;39(5): 456-64. https://doi.org/10.1111/j.1365-2929.2005.02116.x.

8. De Oliveira VF, Bittencourt MF, Navarro Pinto ÍF, Lucchetti ALG, da Silva EO, Lucchetti G. Comparison of the readiness for Interprofessional learning and the rate of contact among students from nine different healthcare courses. Nurse Educ Today. 2018;63:64-8. https://doi.org/10.1016/j.nedt.2018.01.013.

9. Nelson S, White CF, Hodges BD, Tassone M. Interprofessional team training at the Prelicensure level: a review of the literature. Acad Med. 2017;92(5): 709-16. https://doi.org/10.1097/ACM.0000000000001435.

10. Curran VR, Sharpe D, Flynn K, Button P. A longitudinal study of the effect of an interprofessional education curriculum on student satisfaction and attitudes towards interprofessional teamwork and education. J Interprof Care. 2010;24(1):41-52. https://doi.org/10.3109/13561820903011927.

11. Weller JM, Barrow M, Gasquoine S. Interprofessional collaboration among junior doctors and nurses in the hospital setting. Med Educ. 2011;45(5):47887. https://doi.org/10.1111/j.1365-2923.2010.03919.x.

12. Fewster-Thuente $L$, Velsor-Friedrich B. Interdisciplinary collaboration for healthcare professionals. Nurs Adm Q. 2008;32(1):40-8. https://doi.org/10.1 097/01.NAQ.0000305946.31193.61.

13. Long D, Forsyth $R$, ledema R, Carroll K. The (im) possibilities of clinical democracy. Heal Sociol Rev. 2006;15(5):506-19. https://doi.org/10.5172/ hesr.2006.15.5.506

14. Visser CLF, Ket JCF, Croiset G, Kusurkar RA. Perceptions of residents, medical and nursing students about Interprofessional education: a systematic review of the quantitative and qualitative literature. BMC Med Educ. 2017;17(1):77. https://doi.org/10.1186/s12909-017-0909-0.

15. Havyer RD, Nelson DR, Wingo MT, Comfere NI, Halvorsen AJ, Mcdonald FS, et al. Addressing the interprofessional collaboration competencies of the Association of American Medical Colleges: a systematic review of assessment instruments in undergraduate medical education. Acad Med. 2016;91(6):865-88. https://doi.org/10.1097/ACM.0000000000001053.

16. Gambino K, Frawley S, Lu W-H. Working together: addressing cultural diversity, patient safety, and quality care through an Interprofessional health care course. Nurs Educ Perspect. 2019;41(6):1-372. https://doi.org/10.1097/ 01.NEP.0000000000000488.

17. Hawkes G, Nunney I, Lindqvist S. Caring for attitudes as a means of caring for patients-improving medical, pharmacy and nursing students' attitudes to each other's professions by engaging them in interprofessional learning. Med Teach. 2013;35(7):e1302-8. https://doi.org/10.3109/0142159X.2013. 770129.

18. Lehr R. Sixteen S-squared over D-squared: a relation for crude sample size estimates. Stat Med. 1992;11(8):1099-102. https://doi.org/10.1002/sim.478011 0811.

19. Luctkar-Flude M, Hopkins-Rosseel D, Jones-Hiscock C, Pulling C, Gauthier J, Knapp A, Pinchin S, Brown CA Interprofessional infection control education 
using standardized patients for nursing, medical and physiotherapy students. J Interprofessional Educ Pract 2016;2:25-31. doi:https://doi.org/ https://doi.org/10.1016/j.xjep.2016.03.004.

20. Metzler CW, Biglan A, Noell J, Ary D V, Ochs L. A randomized controlled tria of a behavioral intervention to reduce high-risk sexual behavior among adolescents in STD clinics. Behav Ther 2000;31:27-54. doi:https://doi.org/ https://doi.org/10.1016/50005-7894(00)80003-9, 1.

21. Pollard KC, Miers ME, Gilchrist M. Collaborative learning for collaborative working? Initial findings from a longitudinal study of health and social care students. Health Soc Care Community. 2004;12(4):346-58. https://doi.org/1 0.1111/j.1365-2524.2004.00504.x PMID: 15272890.

22. Pollard K, Miers ME, Gilchrist M. Second year scepticism: pre-qualifying health and social care students' midpoint self-assessment, attitudes and perceptions concerning interprofessional learning and working. J Interprof Care. 2005;19(3):251-68. https://doi.org/10.1080/13561820400024225.

23. Rubin RB, Martin MM. Development of a measure of interpersonal communication competence. Commun Res Rep $1994 ; 11(1)$ :33-44. https:// doi.org/https://doi.org/10.1080/08824099409359938.

24. Parsell $\mathrm{G}$, Bligh J. The development of a questionnaire to assess the readiness of health care students for interprofessional learning (RIPLS). Med Educ. 1999;33(2):95-100. https://doi.org/10.1046/j.1365-2923.1999.00298.x PMID: 10211258

25. Luecht RM, Madsen MK, Taugher MP, Petterson BJ. Assessing professional perceptions: design and validation of an interdisciplinary education perception scale. J Allied Health. 1990;19(2):181-91 PMID: 2365636.

26. Polit DF, Beck CT. Nursing Research: Generating and Assessing Evidence for Nursing Practice. 10th ed. Philadelphia: Wolters Kluwer Health; 2017.

27. Nunnaly JC. Psychometric theory. 2nd ed. New York: McGraw-Hill; 1978.

28. Rogers D, Lingard L, Boehler ML, Espin S, Klingensmith M, Mellinger JD, Schindler $\mathrm{N}$. Teaching operating room conflict management to surgeons: clarifying the optimal approach. Med Educ. 2011;45(9):939-45. https://doi. org/10.1111/j.1365-2923.2011.04040.x.

29. Zwarenstein M, Goldman J, Reeves S. Interprofessional collaboration: effects of practice-based interventions on professional practice and healthcare outcomes. Cochrane Database Syst Rev. 2009. https://doi.org/10.1002/14651 858.CD000072.pub2.

30. Chou FC, Kwan CY, Hsin DHC. Examining the effects of interprofessional problem-based clinical ethics: findings from a mixed methods study. J Interprof Care. 2016;30(3):362-9. https://doi.org/10.3109/13561820.2016.114 6877.

31. Freeth D, Hammick M, Koppel I, Reeves S, Barr H. A critical review of evaluations of interprofessional education : WestminsterResearch. London: Higher Education Academy, Health Sciences and Practice Network; 2002. https://westminsterresearch.westminster.ac.uk/item/93wx8/a-critical-reviewof-evaluations-of-interprofessional-education

\section{Publisher's Note}

Springer Nature remains neutral with regard to jurisdictional claims in published maps and institutional affiliations.

Ready to submit your research? Choose BMC and benefit from:

- fast, convenient online submission

- thorough peer review by experienced researchers in your field

- rapid publication on acceptance

- support for research data, including large and complex data types

- gold Open Access which fosters wider collaboration and increased citations

- maximum visibility for your research: over $100 \mathrm{M}$ website views per year

At BMC, research is always in progress.

Learn more biomedcentral.com/submissions 